\title{
Eighteen New Candidate Effectors of the Phytonematode Heterodera glycines Produced Specifically in the Secretory Esophageal Gland Cells During Parasitism
}

\author{
Jason B. Noon, Tarek Hewezi, Thomas R. Maier, Carl Simmons, Jun-Zhi Wei, Gusui Wu, Victor Llaca, \\ Stéphane Deschamps, Eric L. Davis, Melissa G. Mitchum, Richard S. Hussey, and Thomas J. Baum
}

\begin{abstract}
First, third, and twelfth authors: Department of Plant Pathology and Microbiology, Iowa State University, Ames 50011; second author: Department of Plant Sciences, University of Tennessee, Knoxville 37996; fourth, fifth, sixth, seventh, and eighth authors: DuPont Pioneer, Johnston, IA 50131; ninth author: Department of Plant Pathology, North Carolina State University, Raleigh 27695; tenth author: Division of Plant Sciences and Bond Life Sciences Center, University of Missouri, Columbia 65211; and eleventh author: Department of Plant Pathology, University of Georgia, Athens 30602.
\end{abstract}

Accepted for publication 3 April 2015.

\begin{abstract}
Noon, J. B., Hewezi, T., Maier, T. R., Simmons, C., Wei, J., Wu, G., Llaca, V., Deschamps, S., Davis, E. L., Mitchum, M. G., Hussey, R. S., and Baum, T. J. 2015. Eighteen new candidate effectors of the phytonematode Heterodera glycines produced specifically in the secretory esophageal gland cells during parasitism. Phytopathology 105:1362-1372.

Heterodera glycines, the soybean cyst nematode, is the number one pathogen of soybean (Glycine max). This nematode infects soybean roots and forms an elaborate feeding site in the vascular cylinder. H. glycines produces an arsenal of effector proteins in the secretory esophageal gland cells. More than $60 \mathrm{H}$. glycines candidate effectors were identified in previous gland-cell-mining projects. However, it is likely that additional candidate effectors remained unidentified. With the goal of identifying

remaining $H$. glycines candidate effectors, we constructed and sequenced a large gland cell cDNA library resulting in 11,814 expressed sequence tags. After bioinformatic filtering for candidate effectors using a number of criteria, in situ hybridizations were performed in $\mathrm{H}$. glycines wholemount specimens to identify candidate effectors whose mRNA exclusively accumulated in the esophageal gland cells, which is a hallmark of many nematode effectors. This approach resulted in the identification of 18 new $H$. glycines esophageal gland-cell-specific candidate effectors. Of these candidate effectors, 11 sequences were pioneers without similarities to known proteins while 7 sequences had similarities to functionally annotated proteins in databases. These putative homologies provided the bases for the development of hypotheses about potential functions in the parasitism process.
\end{abstract}

Heterodera glycines, the soybean cyst nematode, is a rootinfecting plant-parasitic nematode of the subfamily Heteroderinae (69) and is the most serious pathogen of soybean (Glycine max), causing estimated annual U.S. soybean yield losses of more than $\$ 1$ billion $(11,43,48)$. H. glycines undergoes postembryonic development to the second-stage juvenile (J2) inside its egg and then hatches. Hatched preparasitic J2 (pre-J2) become parasitic (par-J2) when they penetrate soybean roots and migrate intracellularly through cortical parenchyma to the vascular cylinder, where they become sedentary and select an initial feeding cell. Effector proteins secreted into the initial feeding cell suppress plant defenses and initiate the redifferentiation of this cell into a syncytial feeding site composed of numerous fused cells that have undergone cell wall dissolution, resulting in a continuous multinucleated cytoplasm (syncytium) (38). The syncytium provides the essential source of nourishment for the growth and development of the nematode into subsequent sedentary life stages. Although the nematodes complete their postembryonic development through two additional juvenile stages ( $\mathrm{J} 3$ and $\mathrm{J} 4$ ) into adult males and females, continued delivery of effector proteins modulates effective suppression of plant defenses and the full development of the syncytium while also mediating the feeding process.

Corresponding author: T. J. Baum; E-mail address: tbaum@iastate.edu

*The $\boldsymbol{e}$-Xtra logo stands for "electronic extra" and indicates that one supplementary table is published online.

http://dx.doi.org/10.1094/PHYTO-02-15-0049-R

(C) 2015 The American Phytopathological Society
Major factors contributing to the evolutionary success of phytonematodes such as $H$. glycines are their adaptations to plant parasitism $(5,13,37,54)$, which include large specialized secretory gland cells (one dorsal and two subventral) associated with the esophagus. These esophageal glands produce nematode effectors as secretory proteins that are delivered through the hollow nematode mouth spear (stylet) into the plant during parasitism $(37,54)$.

Most known phytonematode effectors are encoded by genes that are expressed exclusively in the three esophageal gland cells $(14,54)$. The dual subventral gland cells are most active during the early stages of parasitism (i.e., during migration and the early events of syncytium formation), whereas the single dorsal gland cell is most active during and following the onset of syncytium formation, which is accompanied by hypertrophy of the dorsal gland cell and, ultimately, atrophy of the subventral gland cells $(13,38)$.

Small suites of parasitism genes that encode phytonematode effectors were first cloned through differential gene expression and target gene identification $(17,45,62,67)$. In the first relatively highthroughput approach toward obtaining comprehensive cohorts of phytonematode candidate effectors (i.e., the parasitome), the contents of the esophageal gland cells were microaspirated at multiple parasitic stages, and the isolated mRNA was used to construct cDNA libraries enriched for candidate nematode effectors $(26,27,36,75)$. Individual clones were sequenced and bioinformatically analyzed for the presence of $\mathrm{N}$-terminal signal peptides (59) and the absence of transmembrane (TM) domains $(44,68)$. Spatial expression of candidate effectors was then assessed by in situ mRNA hybridization (15) in nematode specimens, and approximately 50 new $H$. glycines candidate effectors at that time were identified as exclusively expressed 
in the esophageal glands (27). Interestingly, approximately $75 \%$ of these candidate effectors were considered 'pioneer' sequences without similarities to any sequences in databases at that time.

Since then, several $H$. glycines candidate effectors have been functionally characterized and have been found to exhibit specific subcellular localizations within plant cells $(21,33)$ and to interact with host plant proteins for promoting successful parasitism $(33,54)$ and, thus, were determined to be bona fide effectors. Functional classifications of cyst nematode effectors have revealed complex cell wall modifications for either enhancing migration or for syncytium formation $(26,34,67,73)$, developmental cellular reprogramming through mimicry of plant peptide hormones $(28,64,74,76)$ and modulation of phytohormone transport (47), and suppression and activation of plant defense responses, either through direct interaction with host plant immune regulators $(30,50,60)$ or indirectly through interaction with host plant targets that are associated with defense signaling pathways $(10,35,58)$.

Phytonematode effector characterization provides the potential to develop novel control measures through the manipulation of vulnerable points identified in the parasitic cycle $(13,33,54)$. Because the repertoire of candidate effectors in the potato cyst nematode (Globodera pallida) predicted from a whole genome sequence $(12,70)$ is considerably larger than the cohort obtained from expression analyses (67), it is likely that the current known repertoire of candidate effectors in H. glycines (54) is incomplete. In the current absence of a published robust genome sequence of $H$. glycines, and with the goal of identifying additional novel $H$. glycines candidate effectors that were missed in prior gland-mining projects, a new and significantly larger cDNA library was prepared from the gland region of $H$. glycines, similar to the work described by Gao and colleagues (27) but with minor modifications, as described below.

In this current report, we identified 18 new $H$. glycines candidate effectors that are expressed specifically in the esophageal gland cells, lack canonical endoplasmic reticulum (ER) retention signals, and contain predicted $\mathrm{N}$-terminal signal peptides for likely secretion from the glands and into the plant. Although more than half of these 18 new candidate effectors were found to be pioneer sequences, some showed detectable sequence similarities, which suggested horizontal gene transfer as a possible origin of a few of these sequences in the nematode genome. Furthermore, these similarities also allowed the formulation of biological hypotheses about their function. These candidate effectors include several enzymes that may be involved in the suppression of host cellular defenses, and some that may help weaken physical barriers to infection. Also, some of these new candidate effectors may assist in the formation and function of the syncytium through pathways not previously considered.

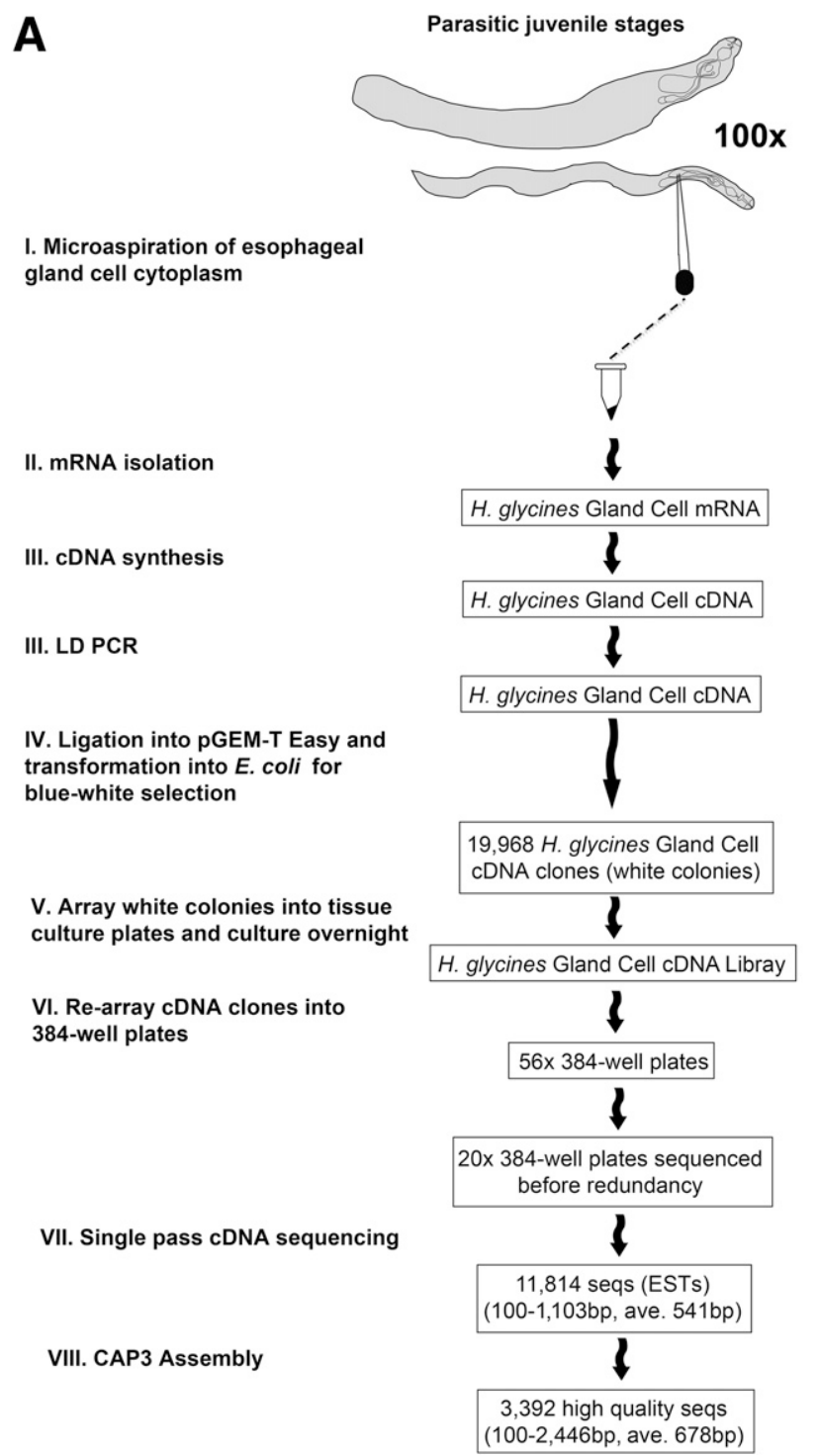

B

I. Must not contain predicted TM domain (TMHMM)

II. Must have moderate enrichment for ESTs (3x or more) from gland cell library relative to whole nematode library constructed by Elling et al. 2007 (blastn)

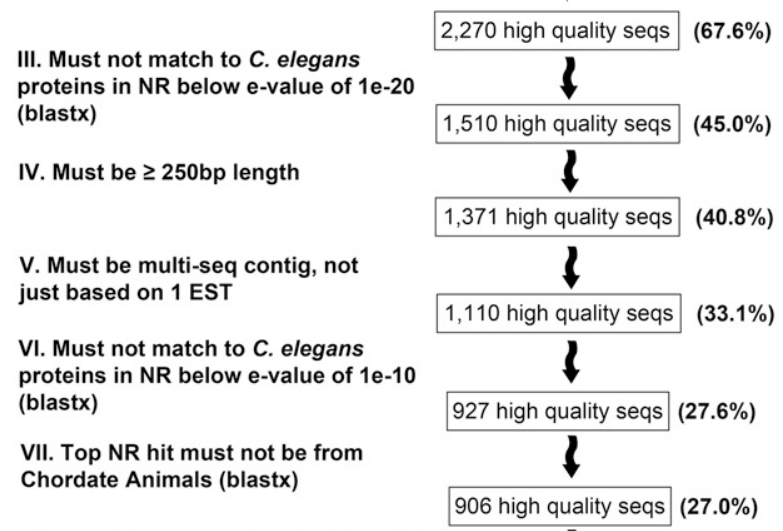

VIII. Must have moderate enrichment for ESTs (7x or more) from gland cell library relative to whole nematode library constructed by Elling et al. 2007 (blastn)
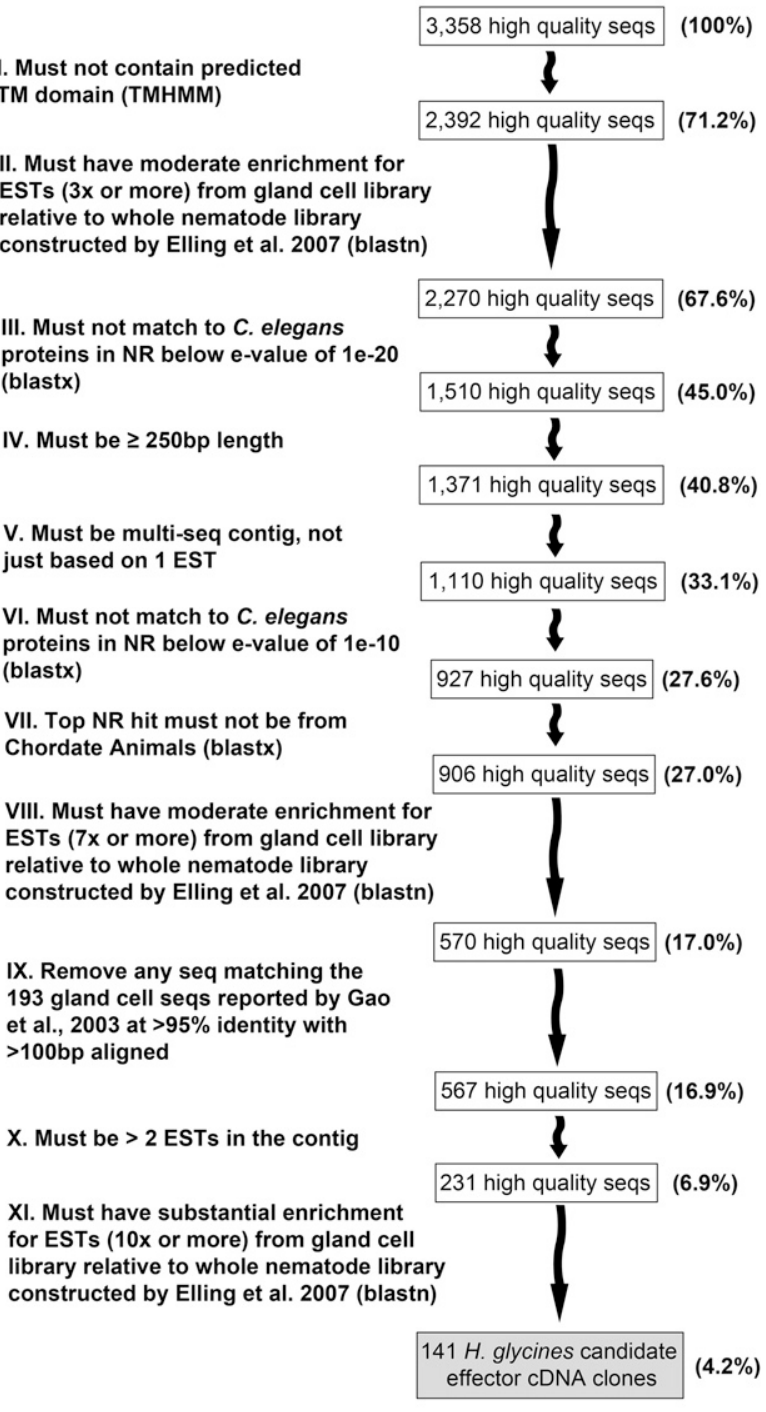

Fig. 1. Overview of methodology. A, Preparation and sequencing of the Heterodera glycines gland cell cDNA library. B, Bioinformatic pipeline for enrichment of candidate $H$. glycines effectors. 


\section{MATERIALS AND METHODS}

Sequence data. Nucleotide and amino acid sequence data have been submitted to the DDBJ/EMBL/GenBank databases. All generated expressed sequence tags (ESTs) are available in dbEST under the accessions JZ682331 to JZ693590, library accession number LIBEST_028433.

$H$. glycines gland cell mRNA purification and cDNA amplification. Parasitic stages of $H$. glycines inbred line OP50 (Fig. 1A) were hand dissected from infected soybean roots, surface sterilized, and embedded in $0.7 \%$ agarose. Esophageal gland cell cytoplasm was microaspirated from $100 \mathrm{H}$. glycines specimens (mixed stages) with glass micropipettes containing $1 \mu \mathrm{l}$ of mRNA extraction buffer (26) and transferred into microcentrifuge tubes for storage at $-80^{\circ} \mathrm{C}$ (Fig. $\left.1 \mathrm{~A}\right)$.

Oligo (dT) ${ }^{25}$ magnetic beads (DynaI, Lake Success, NY) were used to isolate mRNA from the aspirated gland-cell cytoplasm (Fig. 1A). The isolated mRNA was then eluted with 5:1 diethyl pyrocarbonate (DEPC)-treated $\mathrm{H}_{2} \mathrm{O}$ at $70^{\circ} \mathrm{C}$ for 2 min (26). First-strand cDNA synthesis was performed with the Super SMART cDNA Synthesis Kit (Clontech Laboratories, Palo Alto, CA) according to the manufacturer's instructions (Fig. 1A). Mixtures were then diluted with $90 \mu \mathrm{l}$ of Tris-EDTA buffer (10 mM Tris, pH 7.6, and $1 \mathrm{mM}$ EDTA). Longdistance (LD) polymerase chain reaction (PCR) was then performed
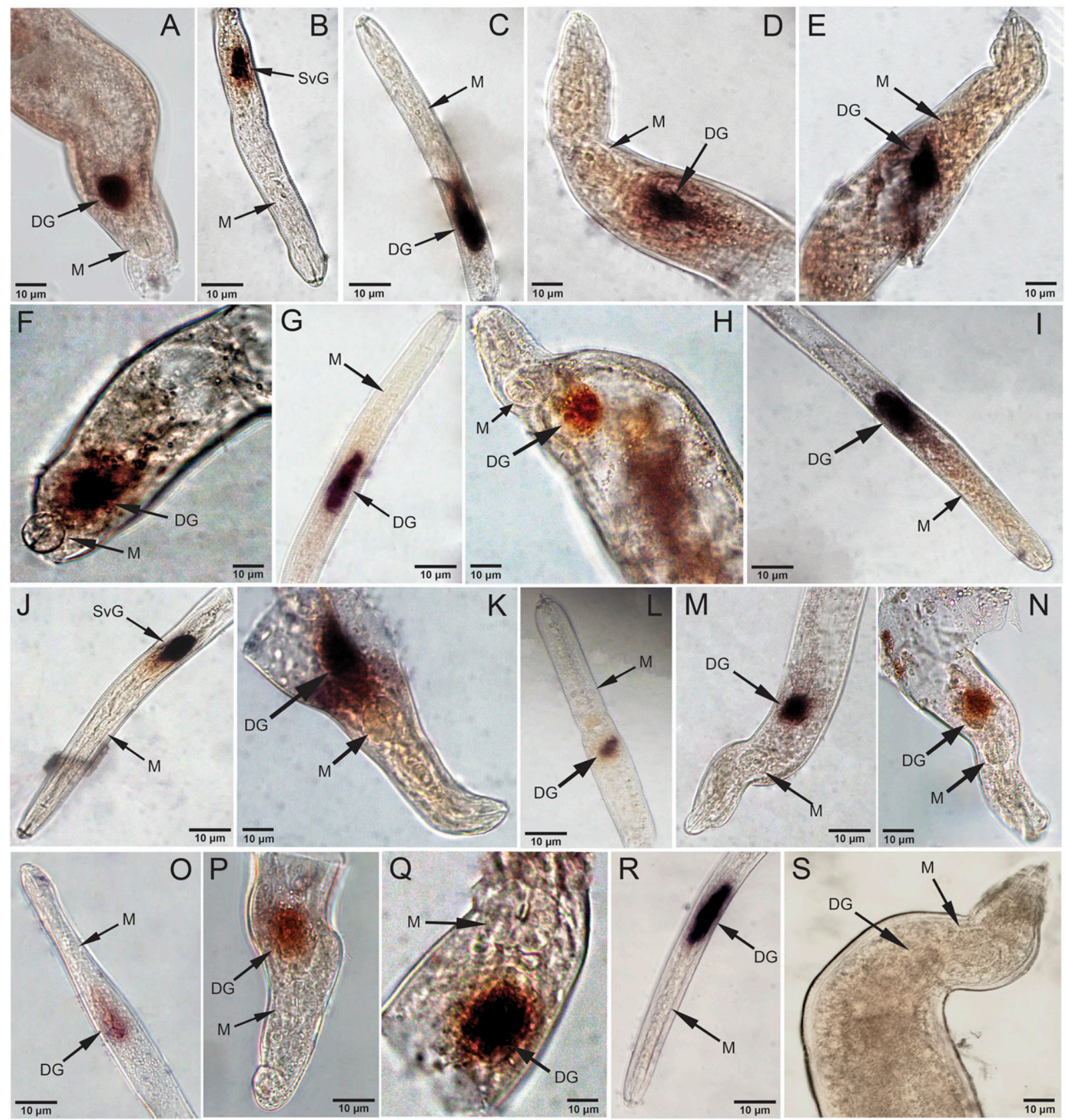

Fig. 2. Hybridization of digoxigenin-labeled antisense DNA probes (dark staining) of the GLAND protein cDNAs to transcripts expressed exclusively within the subventral or dorsal esophageal gland cells of Heterodera glycines. A, GLAND1: parasitic third-stage juvenile. B, GLAND2: migratory preparasitic second-stage juvenile. C, GLAND3: migratory preparasitic second-stage juvenile. D, GLAND4: parasitic third-stage juvenile. E, GLAND5: parasitic third-stage juvenile. F, GLAND6: parasitic third-stage juvenile. G, GLAND7: parasitic second-stage juvenile. H, GLAND8: parasitic third-stage juvenile. I, GLAND9: parasitic secondstage juvenile. J, GLAND10: migratory preparasitic second-stage juvenile. K, GLAND11: parasitic third-stage juvenile. L, GLAND12: parasitic second-stage juvenile. M, GLAND13: parasitic third-stage juvenile. N, GLAND14: parasitic third-stage juvenile. O, GLAND15: parasitic second-stage juvenile. P, GLAND16: parasitic third-stage juvenile. Q, GLAND17: parasitic third-stage juvenile. R, GLAND18: parasitic second-stage juvenile. S, Negative control sense probe of GLAND18: parasitic third-stage juvenile. $\mathrm{DG}=$ dorsal gland cell, $\mathrm{M}=$ metacorpus, $\mathrm{SvG}=$ subventral gland cells. Scale bars equal $10 \mu \mathrm{m}$. 
with $10 \mu \mathrm{l}$ of first-strand reaction solution, $2 \mu \mathrm{l}$ of $10 \mathrm{mM}$ dNTP mix, $10 \mu \mathrm{l}$ of TaqPlus long $10 \times$ low-salt buffer, $1 \mu \mathrm{l}$ of TaqPlus long (Stratagene, La Jolla, CA), and $2 \mu$ of nested universal primer (Clontech Laboratories) (Fig. 1A). LD PCR consisted of hot start followed by an optimum 27 cycles at $94^{\circ} \mathrm{C}$ for $20 \mathrm{~s}, 65^{\circ} \mathrm{C}$ for $30 \mathrm{~s}$, and $72^{\circ} \mathrm{C}$ for $7 \mathrm{~min}$. DEPC-treated $\mathrm{H}_{2} \mathrm{O}$ was used as a negative control at each reaction step above.

Gland-cell cDNA library preparation. The QIAquick PCR purification kit (Qiagen, Valencia, CA) was used to purify the LD PCR-amplified gland cell cDNA (26). Then, the purified cDNA was ligated into pGEM-T Easy (Promega Corp., Madison, WI) at a 3:1 mass ratio (cDNA/plasmid) at $4^{\circ} \mathrm{C}$ overnight (Fig. 1A). The ligated products were then precipitated with $10 \mathrm{mM}$ glycogen and $100 \%$ ethanol, then washed with $70 \%$ ethanol. Purified ligation products were electroporated into competent Escherichia coli XL10-GOLD cells for blue-white selection (Fig. 1A). We handpicked as many white colonies as possible, and transferred them to 96-well Microtest III tissue culture plates (Becton Dickinson, Franklin Lakes, NJ) with $200 \mu \mathrm{l}$ of Luria-Bertani medium and $10 \%$ glycerol and ampicillin $(100 \mu \mathrm{g} / \mathrm{ml})$, and incubated them overnight at $37^{\circ} \mathrm{C}$ (Fig. 1A).

Quality control of the cDNA library was assessed using two methods. First, PCR was performed using the cDNA as template to test whether the four previously identified $H$. glycines candidate effectors 2B10, 3B05, 30D08, and 25G01 could be amplified. Second, EcoRI restriction digests were performed on 24 gland-cell cDNA library clones in order to evaluate insert sizes; empty pGEM-T Easy vector was used as a negative control. From the first test, all four candidate effectors were successfully amplified and, from the second, inserts were found for all 24 clones tested that fell into two size categories: 12 clones were from 0.4 to $1.0 \mathrm{~kb}$ in size and the other 12 clones were from 1.0 to $2.4 \mathrm{~kb}$. Therefore, the quality of the gland-cell cDNA library was determined to be ideal for sequencing.

cDNA sequencing and assembly. The cDNA clones were then rearrayed to 384-well plates (Fig. 1A). Plates were randomly selected for single-pass cDNA sequencing using the SMART forward primer 5'-AAGCAGTGGTATCAACGCAGAGTACGCG-3' and an oligo $(\mathrm{dT})$ reverse primer with equimolar amount of $(\mathrm{T})_{21} \mathrm{~A},(\mathrm{~T})_{21} \mathrm{C}$, and $(\mathrm{T})_{21} \mathrm{G}$ until sequences became redundant (Fig. 1A). Sequences were collected on an ABI 3700 Sequencer (Applied Biosystems, Foster City, CA). Base calls and quality scores were generated from the raw chromotograph files using Phred $(24,25)$. Our own script was used (seqclean) for primary vector-linker cleanup and for removing low quality sequences. The CAP3 program was used to assemble the ESTs into high-quality contiguous sequences (Fig. 1A).

Bioinformatic analyses for enrichment of candidate H. glycines effectors. The high-quality sequences that resulted from the CAP3 program were evaluated using the Spotfire DecisionSite functional genomics software (41). First, we searched for candidate effectors reported by Gao and colleagues (27) using blastn and removed any sequence that resulted in greater than $95 \%$ identity with greater than 100 aligned base pairs. Then, we generated a bioinformatic pipeline to enrich for candidate $H$. glycines effector cDNAs, which consisted of 11 filtering criteria (see Figure 1B for a complete, step-by-step overview). Note that we progressively increased the stringency of our pipeline in order to allow us to better evaluate the kinds of sequences that survived at each step, rather than eliminating them all at once, which also allowed us to better evaluate the quality of our sequence collection. In the first step, the highquality sequences were evaluated for the presence of predicted TM domains using the TMHMM server $(44,68)$. All sequences that contained predicted TM domains while not simultaneously containing predicted signal peptides using SignalP4.0 (59) were removed. In the second step, sequences were evaluated via blastn for having $3 \times$ or more relative enrichment for ESTs from the gland cell library compared with the H. glycines whole-nematode library constructed by Elling and colleagues (21). All sequences that were not enriched $3 \times$ or more for the gland cells relative to whole nematodes were removed. The third step removed all sequences that matched to Caenorhabditis elegans proteins in the nonredundant database (NR) below an E-value of 1E-20 using blastx. In the fourth step, all sequences were removed if they were less than $250 \mathrm{bp}$ in length. The fifth step removed all singletons (unassembled sequences made up of only 1 EST). In the sixth step, all sequences that matched to C. elegans proteins in NR below an E-value of 1E-10 using blastx were removed. In the latter step, we used such a high stringency to largely avoid testing any sequence that contained significant similarity to sequences from a free-living ancestor, thereby increasing our confidence in the candidate sequences encoding effectors rather than proteins common to nonparasitic organisms. Although additional phytonematode effectors may contain domains shared with C. elegans proteins, we chose not to allow for such flexibility because this would probably have largely increased the number of false positives that would have made it through our pipeline. Using blastx against NR, step seven removed any sequence that retrieved a protein from chordate animals as the best match. In step eight, sequences were evaluated via blastn for having $7 \times$ or more relative enrichment for ESTs from the gland cell library compared with the H. glycines wholenematode library constructed by Elling and colleagues (21). Step nine removed any sequence that matched to the $193 \mathrm{H}$. glycines gland cell cDNA sequences obtained by Gao and colleagues (27) at greater than $95 \%$ identity and with greater than $100 \mathrm{bp}$ aligned using blastn. In step 10, sequences were removed if they did not contain more than two ESTs in the contig. Finally, in step 11, sequences were evaluated via blastn for having $10 \times$ or more relative enrichment for ESTs from the gland cell library compared with the $H$. glycines whole-nematode library constructed by Elling and colleagues (21).

Developmental expression of candidate effectors. For all 141 gland-cell cDNA clones that passed the bioinformatic filtering (Fig. 1), specific forward and reverse primers were used to synthesize digoxigenin (DIG)-labeled sense and antisense DNA probes (Boehringer, Mannheim, Germany) by asymmetric PCR (26). In situ hybridizations were performed on fixed, permeabilized preparasitic and mixed parasitic $H$. glycines stages $(15,26)$. Alkaline phosphatase conjugated anti-DIG antibody and substrate were used to detect probes that hybridized within the nematode specimens (15). The specimens were observed with a Zeiss Axiovert inverted compound light microscope.

Gene model predictions. We performed blastn searches with the nucleotide sequences from all gland-positive cDNA clones against a draft $H$. glycines genome sequence (M. Hudson and K. Lambert, personal communication) with an E-value cutoff of 1E-10. For each clone, the sequence within the scaffold that aligned at nearly $100 \%$ identity, including the $5^{\prime}$ - and 3 '-flanking sequences, were submitted to the self-training eukaryote gene prediction software GeneMark.hmm (49) using the test set from the C. elegans genome. For each of the resulting gene models, the exon sequences were combined and translated with the ExPASy Translate tool to obtain the resulting putative full-length protein sequences. Finally, for predicting the $\mathrm{N}$-terminal signal peptides, we used the software SignalP4.0 with the following parameters: Organism group = eukaryotes, default D-cutoff value $=0.50$ for SignalP-TM networks, method $=$ input sequences may include TM regions.

Protein sequence similarity searches and domain analyses. To search for putative homologs of the identified $H$. glycines candidate effectors, blastp and PSI-blastp (2) searches were performed against NR with E-value cutoffs equal to 0.001. To search for conserved protein domains, both blastp, with the Conserved Domains Database (CDD) v3.11-45746 position specific scoring matrices (PSSMs) (52), and InterProScan (63) were used with default parameters.

\section{RESULTS}

Sequencing and bioinformatic analysis of an $\boldsymbol{H}$. glycines gland cell cDNA library. We constructed a cDNA library from 
the esophageal gland cells of $H$. glycines that contained 19,968 plasmid cDNA clones (Fig. 1A). As detailed in the Materials and Methods section, our sequencing generated 11,814 sequences (i.e., ESTs) of 100 to $1,103 \mathrm{bp}$ in length and an average length of $541 \mathrm{bp}$ (Fig. 1A). Sequence assembly produced 3,392 distinct high-quality cDNA sequences with an average length of $678 \mathrm{bp}$ and totaling $2.3 \mathrm{Mbp}$ of unique sequence (Fig. 1A).

In order to assess the quality of this gland cell library, we searched the list of 3,392 high-quality sequences for the candidate effectors reported by Gao and colleagues (27). We identified sequences representative of 34 of the 53 candidate effectors (64\%) that were reported by Gao and colleagues (27) (Supplementary Table S1), all of which were removed from the list, which reduced the number of high-quality sequences to 3,358 . The absence of 19 effectors (36\%), all of which were pioneers, could be due to either technical differences such as different sampling times or different extraction and processing details or differences between the two $H$. glycines populations used. Nonetheless, rediscovering the majority of the candidate effectors reported by Gao and colleagues (27) was indicative that the quality of the gland cell library and sequencing was suitable for downstream analyses.

In all, 11 bioinformatic filtering criteria were established in order to eliminate sequences that were unlikely to be gland-specific in expression and to enrich for possible candidate effectors (Fig. 1B). This set of filtering criteria reduced the 3,358 high-quality sequences to $141(4.2 \%)$. These retained sequences all fulfilled the following criteria: (i) comprising more than two ESTs, (ii) different from the gland cell sequences generated by Gao and colleagues (27), (iii) unique from protein sequences of $C$. elegans and chordate animals, and (iv) without TM domains (Fig. 1B).

Gao and colleagues (27) performed nematode in situ hybridization screens on a total of 193 cDNA clones, of which 140 did not localize to the gland cells. As a testimony to the stringency of our filtering pipeline, our sequences retained after filtering (steps one through eight) only contained 3 of these 140 nongland-cell-specific sequences (Fig. 1B, step nine). In other words, this result indicated that the high stringencies of steps one through eight of our filtering pipeline were successful at removing nongland-cell-specific sequences.

Screening for gland-cell-specific mRNA accumulation. To test for gland-cell-specific mRNA expression in $H$. glycines specimens, we used DIG-labeled sense and antisense DNA probes from all 141 sequences in whole-mount nematode in situ mRNA hybridization tests. These analyses resulted in the identification of 18 distinct cDNA clones whose antisense probes hybridized to mRNA transcripts accumulating within the subventral ( 2 clones) or dorsal ( 16 clones) gland cells of $H$. glycines (Fig. 2). We designated these 18 sequences as GLAND1 through 18. All remaining cDNA clones either hybridized to tissues or cells other than the esophageal glands, showed nonspecific hybridization patterns, or could not be localized in $H$. glycines specimens. None of the negative control sense probes showed any hybridization within $H$. glycines specimens (Fig. 2S).

Of the 18 gland-positive cDNA clones identified, 9 clones were missing the complete $\mathrm{N}$-termini of their encoded proteins and could not be scrutinized for the presence of a predicted $\mathrm{N}$-terminal signal peptide for secretion. However, we were able to access an unpublished $H$. glycines draft genome (M. Hudson and $\mathrm{K}$. Lambert, personal communication) to search for all 18 glandpositive cDNAs in order to identify complete full-length coding sequences. High-scoring scaffolds were identified from the draft genome sequence for all 18 gland-positive cDNA clones. Gene model predictions resulted in the identification of putative full-length protein sequences for all 18 clones. Importantly, we identified at least one intron in 17 of the 18 genes (Fig. 3). The only gene that was not found to contain any introns was GLAND9 (Fig. 3), which was found to be, by far, the smallest of the GLAND proteins encoding a peptide of only 94 amino acids (Table 1). Thus, these findings, in addition to the observed gland-cell-specific expressions (Fig. 2), indicated that the 18 sequences are encoded by the nematode genome and not contaminants.

Subsequently, all 18 candidates were confirmed to encode predicted $\mathrm{N}$-terminal signal peptides, including the 9 clones that were originally missing their complete $\mathrm{N}$ termini of the encoded proteins (Fig. 3; Table 1). We next searched the protein sequences of all 18 candidates for the presence of a C-terminal animal (KDEL)- or yeast (HDEL)type ER retention signal and for possible ER retrieval signals matching the $\mathrm{N}$-terminal XXRR and C-terminal KKXX motifs with PSORT II (55). None were predicted to contain an ER retention signal, and GLAND12 was the only candidate predicted to contain a possible ER retrieval signal matching the KKXX motif, KKRA, at the $C$ terminus. However, because predicted ER retrieval signals (XXRR and KKXX) are neither necessary nor sufficient for localization of proteins to the ER membrane, there is no significance associated with this prediction (55). Thus, the lack of ER retention signals indicated that the 18 candidate proteins are unlikely localized in the ER of the gland cells. Furthermore, because Golgi-resident proteins are dependent on the properties of TM domains (6), which none of the 18 candidates were found to contain, the encoded proteins are unlikely localized to the Golgi of the gland cells. Thus, we have identified 18 new gland-specific cDNA clones that encode secretory peptides that do not contain TM domains and are likely secreted from the gland cells. GLAND1 through 18 can be regarded as new $H$. glycines candidate effectors (Table 1).

Gland cell expression throughout $\boldsymbol{H}$. glycines development. The timing of candidate effector gene expression during the life cycle frequently is informative when trying to infer effector function. Therefore, we qualitatively assessed in situ hybridization profiles of the 18 new candidate effectors in different developmental stages (Table 1). Among the 18 candidate effectors, 3 were most active during migratory (GLAND10) and early parasitic J2 (GLAND7 and 9) stages. Interestingly, only one of these three was expressed in the subventral gland cells (GLAND10), although this cell type is typically most active during these early time points. Eleven candidate effectors were most active during sedentary parasitic stages (GLAND1, 4 to 6,8 , and 11 to 17) and, as expected, all were expressed in the dorsal gland cell. The remaining three candidate effectors (GLAND2, 3, and 18) were highly active throughout the entire life cycle. Of these, one was expressed in subventral gland cells (GLAND2) whereas GLAND3 and 18 were localized in the dorsal gland cell. These data suggest that GLAND7, 9, and 10 likely function during the migratory phase or the early sedentary phase of syncytium induction. On the other hand, GLAND1, 4 to 6, 8, and 11 to 17 likely function during syncytium formation or feeding. Finally, GLAND2, 3, and 18 appear to be important throughout the parasitic life cycle of $H$. glycines.

GLAND proteins with putative homologs in databases. To search for putative nonphytonematode homologs for GLAND proteins 1 to 18 , blastp was performed against NR. Six GLAND proteins (GLAND2, 8, 9, 11, 12, and 18) did not match any known sequences below the cutoff E-value of 0.001 and, thus, were immediately designated as pioneers (Table 1). Eight GLAND proteins matched only to other cyst nematode sequences. The top hit for GLAND3 was the previously identified $H$. glycines candidate effector 12H04 (GenBank accession AAO85452.1), with an E-value of 8.00E87. However, large portions of the GLAND3 sequence do not align to $12 \mathrm{H} 04$; thus, the similarity is only partial. The top hit (E-value of 3.00E-26) for GLAND4 was the 3E10 isoform of the potato cyst nematode G. rostochiensis 1106 candidate effector family (GenBank accession AFH68219.1). GLAND5 hit to the previously identified $H$. glycines candidate effector 11A06 (GenBank accession AAP30754.1) with an E-value of 4.00E-96, while the top hit (E-value of 2.00E-104) for GLAND6 was the previously identified H. glycines candidate effector 4D06 (GenBank accession AAN32892.1). Although the sequence similarities between GLAND5 and 11A06 and GLAND6 and 4D06 are high, there are significant amino acid differences that distinguish these protein pairs (16 and 12\% different amino acids, respectively). Hence, GLAND5 and GLAND6 are 


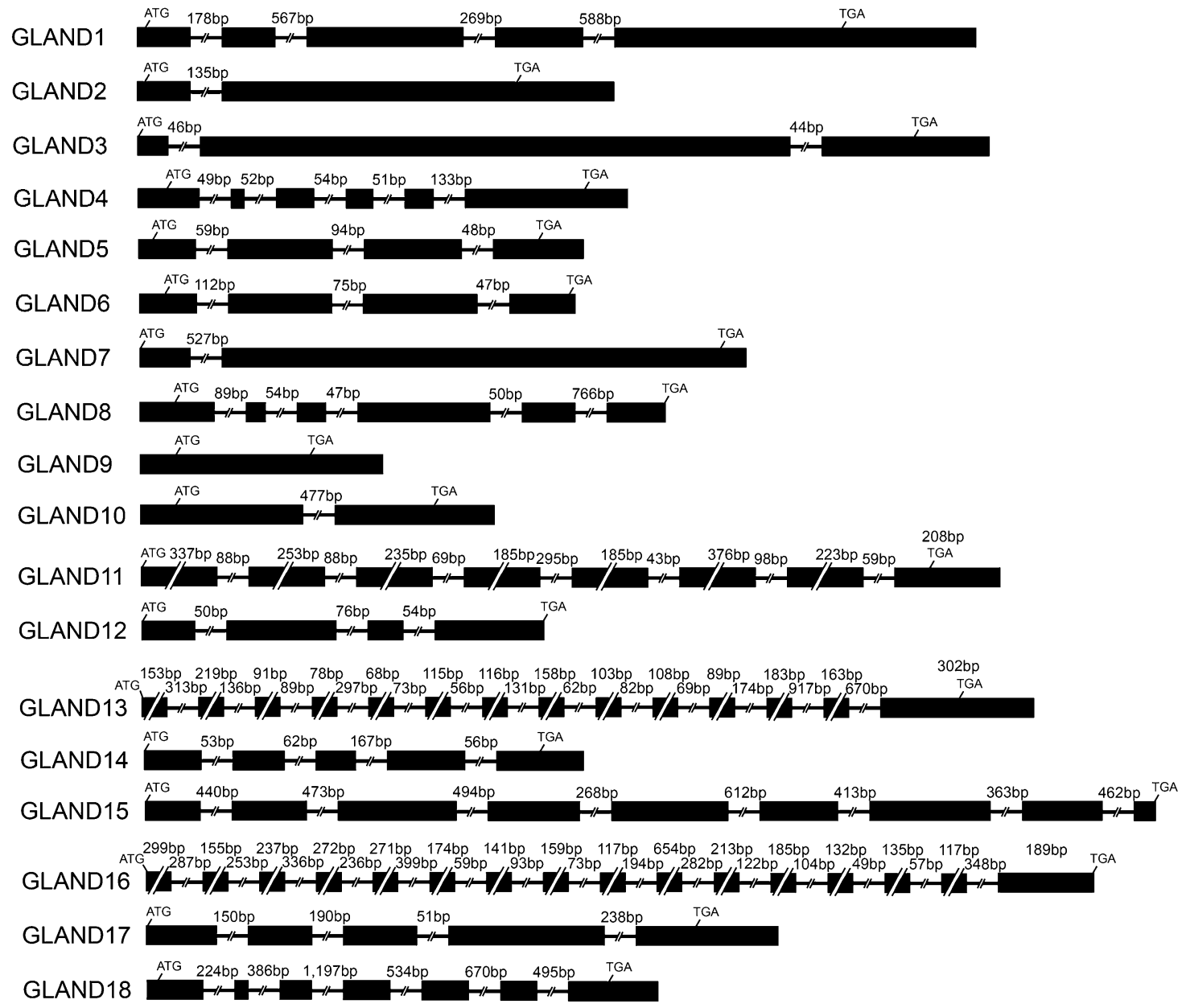

Fig. 3. Gene models for Hg-GLAND1 to 18. Gene model predictions were made for the sequences within the draft Heterodera glycines genome that aligned with highest similarities to $\mathrm{Hg}$-GLANDI to 18 . Exons are illustrated as black boxes and introns as horizontal lines. All introns are drawn with equal sizes for ease of presentation - the actual sizes are shown above. Exons for GLAND11, 13, and 16, except for the last exons for accurate placement of the stop codons, are also drawn equal in size within each gene for ease of presentation because these genes are much larger than the rest-the actual exon sizes are also shown above. Start and stop codons are also indicated above the respective exons for each gene.

TABLE 1. Summary of the 18 GLAND proteins preceded by signal peptides for secretion and whose mRNAs are expressed exclusively in the esophageal gland cells of Heterodera glycines

\begin{tabular}{|c|c|c|c|c|c|c|c|c|}
\hline \multirow[b]{2}{*}{ Clone } & \multirow[b]{2}{*}{ Accession $^{\mathrm{b}}$} & \multirow[b]{2}{*}{ Signal peptide ${ }^{c}$} & \multirow[b]{2}{*}{ Protein $^{\mathrm{d}}$} & \multirow[b]{2}{*}{ Highest protein similarity } & \multirow[b]{2}{*}{ E-value } & \multicolumn{3}{|c|}{ Gland expression $^{\mathrm{a}}$} \\
\hline & & & & & & Pre-J2 & Par-J2 & $\mathrm{J} 3-\mathrm{A}$ \\
\hline GLAND1 & KJ825712 & Yes, $\mathrm{D}=0.787$ & 419 & GNAT, Streptomyces* & $1 \mathrm{E}-21$ & - & DG & DG \\
\hline GLAND2 & KJ825713 & Yes, $D=0.934$ & 234 & Pioneer & & $\mathrm{SvG}$ & $\mathrm{SvG}$ & $\mathrm{SvG}$ \\
\hline GLAND4 & KJ825715 & Yes, $D=0.866$ & 167 & 1106_3E10, G. rostochiensis & $3 \mathrm{E}-26$ & - & DG & DG \\
\hline GLAND5 & KJ825716 & Yes, $D=0.861$ & 187 & G11Ā06, H. glycines & 4E-96 & - & - & DG \\
\hline GLAND6 & KJ825717 & Yes, $D=0.846$ & 203 & 4D06, $H$. glycines & $2 \mathrm{E}-104$ & - & - & DG \\
\hline GLAND10 & KJ825721 & Yes, $\mathrm{D}=0.787$ & 155 & CBP, H. schachtii & 4E-09 & SvG & - & - \\
\hline GLAND11 & KJ825722 & Yes, $\mathrm{D}=0.810$ & 611 & Pioneer & $\ldots$ & - & - & DG \\
\hline GLAND12 & KJ825723 & Yes, $D=0.541$ & 201 & Pioneer & $\ldots$ & - & DG & DG \\
\hline GLAND13 & KJ825724 & Yes, $D=0.618$ & 595 & Invertase, Rhizobium* & $8 \mathrm{E}-37$ & - & DG & DG \\
\hline GLAND14 & KJ825725 & Yes, $D=0.634$ & 170 & Endopeptidase, A. suum* & $7 \mathrm{E}-55$ & - & - & DG \\
\hline GLAND15 & KJ825726 & Yes, $\mathrm{D}=0.837$ & 496 & G23G11, $H$. glycines* & $4 \mathrm{E}-05$ & - & DG & DG \\
\hline
\end{tabular}

${ }^{a}$ In situ hybridization of antisense DNA probes to mRNA specifically within the dorsal esophageal gland cell (DG) or subventral esophageal gland cells (SvG) in preparasitic second-stage juveniles (Pre-J2), parasitic J2 (Par-J2), or parasitic J3, J4, or young adult stages (J3-A) of Heterodera glycines; - indicates not detected.

b Sequences submitted to GenBank.

c Signal peptides were predicted with the SignalP 4.0 software. The D-value cutoff was set to 0.5 .

${ }^{\mathrm{d}}$ Listed are the number of amino acids in the predicted protein sequences.

e GLAND proteins listed with asterisks were found to contain domains from either InterProScan or the Conserved Domains Database. 
likely within candidate effector families containing 11A06 and 4D06, respectively, but they may have completely different functions or host targets. The top hit (E-value of 3.00E-116) for GLAND7 was the previously identified putative $H$. glycines gland protein G15A10 (GenBank accession AAP30765.1). Although the E-value is very low, much of the GLAND7 sequence is unique and does not align with G15A10. G15A10 was not tested by in situ hybridization when initially identified (27) because the missing $5^{\prime}$ sequence prevented the prediction of a signal peptide. Given our new data with GLAND7, it now is likely that G15A10 also is an $\mathrm{H}$. glycines candidate effector. The top hit (E-value of 4.00E-09) for GLAND10 was the functionally characterized cellulose-binding protein effector of $H$. schachtii (GenBank accession ABY49997.1) (25,34), however, 67\% of the amino acids are different. GLAND15 hit to another previously identified putative $H$. glycines gland protein, G23G11 (GenBank accession AAP30771.1; E-value of 4.00E-05). Similar to G15A10, G23G11 also was not tested by in situ hybridization due to a missing 5 '-end sequence and, thus, G23G11 also likely is an $H$. glycines candidate effector. The top hit for GLAND16 was the previously identified chorismate mutase candidate effector of $H$. glycines (GenBank accession AAO19577.2; E-value of 4.00E-23); however, GLAND16 is over four times larger. Four GLAND proteins hit to nonphytonematode sequences. The top hit for GLAND1 was a GCN5-related N-acetyltransferase from the genus Streptomyces (GenBank accession WP_030417594.1), with an E-value of 1.00E-21. The top hit for GLAND13 was a $\beta$-fructofuranosidase of Rhizobium leguminosarum (GenBank accession WP_003572067.1), with an E-value of 8.00E-37. GLAND14 hit to a prolyl endopeptidase of Ascaris suum (GenBank accession ERG83141.1), with an E-value of 7.00E-55. Finally, GLAND17 hit to isoform C of protein DUO-3 from C. elegans (GenBank accession CDH93266.1), with an E-value of 2.00E-04 (Table 1).

We next used the InterProScan software to search for conserved domains within the 18 GLAND proteins to gain further insight into their potential functions. Aside from $\mathrm{N}$-terminal unintegrated signal peptides that were again predicted in all 18 GLAND proteins, InterPro domains were identified in only the four GLAND proteins $1,13,14$, and 16 (Table 2). All domains found in these four GLAND proteins are consistent with their putative homologies (Table 1).

TABLE 2. Domains identified in six GLAND proteins

\begin{tabular}{lc}
\hline Clone & $\begin{array}{c}\text { Descriptions of predicted domains } \\
\text { (InterProScan or CDD) }\end{array}$ \\
\hline GLAND1 & GNAT (InterPro:IPR000182), Acyl-CoA \\
N-acyltransferase (InterPro:IPR016181) \\
Glycosyl hydrolase, family 32 (InterPro: \\
IPR001362), Concanavalin A-like \\
lectin/glucanases superfamily (InterPro: \\
IPR008985), Glycosyl hydrolase family \\
32, N-terminal (InterPro:IPR013148), \\
Glycosyl hydrolase family 32, C-terminal \\
(InterPro:IPR013189), Glycosyl hydrolase, \\
five-bladed $\beta$-propellor (InterPro: \\
IPR023296) \\
Peptidase S9, prolyl oligopeptidase, catalytic \\
domain (InterPro:IPR001375), Peptidase \\
S9A, prolyl oligopeptidase (InterPro: \\
GLAND14 & IPR002470) \\
& MPN (CDD:cd08064) \\
Chorismate mutase (InterPro:IPR002701), & Chorismate mutase, type II (InterPro: \\
GLAND15 & IPR020822) \\
OTU-like cysteine protease (CDD: & pfam02338) \\
\hline
\end{tabular}

a All 18 GLAND proteins were analyzed with InterProScan for the presence of InterPro domains. GLAND proteins without InterPro domains were then analyzed with $\mathrm{CD}$-search using blastp at the National Center for Biotechnology Information to search for conserved domains from the Conserved Domains Database (CDD).
Although InterPro domains were not identified in either GLAND15 or GLAND17, conserved domains from the CDD were identified from our blastp searches using default parameters in both protein sequences. An MPN domain was identified in GLAND15 and an OTU-like cysteine protease domain in GLAND17 (Table 2).

\section{DISCUSSION}

A central question for plant-parasitic nematodes is how many of their estimated 15,000 to 20,000 protein-coding genes are directly involved in parasitism. Gao and colleagues (27) obtained a sizable profile of the $H$. glycines parasitome (i.e., the set of genes that encode the candidate effector proteins) that greatly added to the list of candidate effectors from any phytonematode that had been identified in prior studies $(17,26,45,62,67,75)$. Gao and colleagues (27) identified 51 new candidate effectors at that time as being expressed specifically in the esophageal gland cells and that were all predicted to encode secreted proteins without TM domains, bringing the total $H$. glycines parasitome to 64 . This work resulted from the filtering of 2,229 high-quality sequences that were derived from a gland-cell-enriched cDNA library. Here, we generated and sequenced an $H$. glycines gland-cell-enriched cDNA library that resulted in 3,392 high-quality sequences (Fig. 1A), of which 18 were determined to be new $H$. glycines candidate effectors based on the presence of $\mathrm{N}$-terminal signal peptides for secretion, lack of TM domains and canonical ER localization signals, and gland-localized mRNA expressions. Although this brings the total number of H. glycines candidate effector genes to approximately 82 , we have no way of confidently predicting the actual number of effector genes in the $H$. glycines parasitome. However, because we obtained over 1,000 more high-quality sequences than Gao and colleagues (27) but accomplished a much lower discovery percentage for new effectors $(0.53 \%$ versus $2.29 \%)$, our study likely is very close to exhausting the discovery of additional $H$. glycines candidate effectors.

Our sequencing for this study was performed before the publication of our recent, more comprehensive approach, where whole gland cells were isolated and subjected to next-generation sequencing (51); hence, here we still used the traditional approach for generating ESTs, consistent with Gao and colleagues (27). It will be interesting to compare the effectiveness of the method used by Gao and colleagues (27) and by us here with that developed by Maier and colleagues (51) for the identification of new $H$. glycines effectors. Furthermore, it will be of particular interest to evaluate the relative abundances in the gland cells of previously identified candidate effectors and the effectors reported here by us (GLAND1 to 18), as well as comparing these relative abundances between different $H$. glycines populations.

The paradigm for secretion of phytonematode effectors from the esophageal gland cells is the classical secretory pathway $(13,54)$. In addition to aligning our 18 gland-positive cDNAs to the unpublished, draft $H$. glycines genome, we aligned the remaining 123 candidate cDNAs that did not result in gland-specific expression but that all had undergone and passed the same filtering process as the 18 GLAND genes, predicted the gene structure for each aligned scaffold, and analyzed for the presence of $\mathrm{N}$-terminal signal peptides. Interestingly, the majority of these nongland-specific cDNAs were not found to contain signal peptides for secretion. Because no cDNAs were found to be gland specific in expression without simultaneously containing $\mathrm{N}$-terminal signal peptides, we have found a perfect correlation between gland-specific expression in the nematode and the presence of a predicted $\mathrm{N}$-terminal signal peptide for secretion in our filtered sequence set. Therefore, these findings are in strong support of the classical secretory pathway being the predominant mode of secretion of phytonematode effectors from the gland cells.

Substantial portions of the parasitomes of phytonematodes have been demonstrated to consist of candidate effector sequences that lack detectable similarities to nonphytonematode, annotated sequences in databases, which are referred to as pioneers $(22,27)$. It has been suggested that these pioneer candidate effectors are 
a result of faster-evolving sequences due to interactions with the host (22). Gao and colleagues (27) identified $51 \mathrm{H}$. glycines candidate effectors, of which 38 were designated as pioneers (75\%). In our study, 11 of the 18 new candidate effectors $(61 \%)$ identified were either designated as pioneers or showed similarity only to other phytonematode candidate effectors designated as pioneers. Only seven of the new candidate effectors identified resulted in similarity to nonpioneer sequences (Table 1) or contained predicted protein domains (Table 2). Thus, our findings reinforce the previous observations of pioneer candidate effectors predominating in phytonematode parasitomes. However, because our bioinformatic pipeline removed all sequences that significantly matched to proteins from C. elegans, it may be even more informative in future projects to test some of the sequences that would have otherwise survived the pipeline for gland-cell mRNA accumulations.

Horizontal gene transfer (HGT) is well described for phytonematodes $(5,29,67)$. It has been concluded that large suites of various noneffector and effector enzymes, including those involved in cell wall degradation in phytonematodes, were acquired from either plant-associated ancestral bacteria or fungi by HGT, because the phytonematode sequences had high similarity to enzymes from these types of organisms but no free-living or animal parasitic nematodes were found to contain such enzymes $(5,29)$. Here, we identified an $H$. glycines candidate effector (GLAND1) that is expressed in the dorsal gland during sedentary parasitic stages and that has high sequence similarity to GCN5-related $\mathrm{N}$-acetyltransferases (GNAT) from bacterial species preferentially within the Streptomyces genus (Table 1). No such homologs are identified for the GLAND1 protein in other phytonematodes, animalparasitic nematodes, or any free-living nematodes in blastp analysis against the NR database. However, more comprehensive analyses of phytonematode genomes must be performed in order to determine whether GLAND1 is present in only certain species or more broadly conserved throughout phytonematodes. Because streptomycetes are saprophytes and, thus, in physical association with phytonematodes, it can be suggested that GLAND1 might have been acquired via HGT from ancestral bacteria similar to streptomycetes. Furthermore, effector genes coding for acetyltransferases have been identified from a number of bacterial pathogens with functional roles in suppressing host immune responses $(46,57,77)$. However, effectors from the GNAT superfamily remain extremely rare. GNATs are the most widely distributed acetyltransferase systems functioning in diverse biological processes, including antibiotic resistance (20), sclerotization and neurotransmitter inactivation in insects (31), various chromatin modifications (39), and regulation of polyamine metabolism (9), among others. The GNAT effector from Mycobacterium tuberculosis is the only pathogen effector belonging to the GNAT superfamily to be reported thus far (42). Similar to the $M$. tuberculosis GNAT effector, we speculate that GLAND1 may function by inhibiting defense signaling in plant cells during cyst nematode parasitism but, given the published roles of GNATs in a broad range of biological processes, as mentioned above, other functions are equally possible.

In plants, invertases ( $\beta$-fructofuranosidases) are crucial enzymes for metabolizing sucrose into glucose and fructose, as well as for sucrose transport (32). Host plant invertases have been implicated in increasing the metabolic sink potential of giant cells formed by the root-knot nematode Meloidogyne incognita (40), which is supported by the nematode's vital need for sucrose-derived carbohydrates such as fructose (61). Also, invertases were identified in $M$. incognita during whole-genome sequencing and proposed to have been acquired from the plant-symbiotic nitrogen-fixing bacteria of the genus Rhizobium through HGT due to highest similarity to sequences from these bacteria. It was hypothesized that these invertases serve to enhance the processing of plant-derived nutrients within the nematode, because no signal peptides for secretion were present in the protein sequences (1). On the other hand, recent wholegenome sequencing of $G$. pallida (potato cyst nematode) identified four genes that encode secreted invertases that are similar to the Meloidogyne invertases (12). However, the possibilities of these secreted invertases in G. pallida being acquired through HGT from Rhizobium spp. and being potential nematode effectors were not discussed, nor was their gland-specific expression scrutinized. Here, we identified an $H$. glycines secretory invertase (GLAND13) and, like the predicted protein found in M. incognita, GLAND13 is most similar to invertase enzymes from bacteria, preferentially within the Rhizobium genus (Table 1). However, we were able to show that GLAND13 is expressed exclusively in the dorsal gland during the feeding stages of parasitism (Table 1) and, thus, this $H$. glycines secreted invertase is likely an effector. This discovery may also suggest that the four secreted invertases in G. pallida are candidate effectors and likewise potentially acquired through HGT from Rhizobium. The possibility of these invertases being present in phytonematodes through HGT from Rhizobium spp. is supported by the evidence that these bacteria were likely the predominant group of "donor" bacteria partially responsible for nematode adaptations toward phytoparasitism (66). However, because there has not yet been a deep phylogenetic analysis performed on phytonematode invertases, it still remains inconclusive whether or not the origins of these genes were from bacteria via HGT. Taken together, these results would suggest that cyst nematodes might increase the metabolic sink of syncytia by synthesizing and secreting their own plant nutrient-processing enzymes into the plant.

Animal-parasitic nematodes have been shown to secrete various proteases to break down host barriers during infection. For example, the entomopathogenic nematode Steinernema carpocapsae secretes a serine protease that facilitates invasion of the host insect gut wall, a physical barrier that opposes pathogen invasion (71). Although many proteases have been identified in phytonematodes, predominantly $M$. incognita (1), and have been shown to be expressed in the intestine (56) and implicated in nematode reproduction and embryogenesis (3), phytonematode effectors secreted and delivered into the plant that possess proteolytic activity have not been identified. Here, we identified two putative $H$. glycines candidate effector proteases, GLAND14 and 17, expressed specifically in the dorsal gland during later parasitic stages (Table 1). GLAND14 is most similar to an uncharacterized serine prolyl endopeptidase from the parasitic nematode $A$. suum and is made up entirely of serine protease catalytic domains (Table 2). Because serine proteases are the most abundant proteolytic enzymes, are conserved throughout life, and possess diverse biological functions (including digestion, fibrinolysis, development, blood coagulation, apoptosis, and immunity) (16), it is difficult to speculate about the specific role that a serine protease effector would have during phytonematode parasitism, or whether host protein targets would be specific or more broad. However, because GLAND14 resulted in mRNA accumulation in the dorsal gland cell in only late parasitic stages, we speculate that GLAND14 may target and cleave host plant proteins to weaken host defenses (53) rather than aid in the formation of the syncytium. Furthermore, sequence similarity and prediction of an OTU-like cysteine protease domain, which functions for deubiquitylation (4), in GLAND17 (Tables 1 and 2) might suggest that this candidate effector functions as a deubiquitylating enzyme during parasitism, which may be interesting given the reciprocal finding of ubiquitin like effectors in phytonematodes $(10,27,72)$.

The MPN domain is diverse, found in subunits of multiprotein complexes from the $26 \mathrm{~S}$ proteasome to the COP signalosome to subunits of eukaryotic translation initiation factor 3, as well as in regulators of transcription and translation (65). The consensus of proposed biological functions is the involvement in protein degradation, either through direct proteolytic activity, ubiquitin binding for subsequent ubiquitylation, or direct association with the proteasome (65). Therefore, because an MPN domain was identified in GLAND15, we propose participation in protein degradation within the syncytium as a tempting hypothesis for the function of this candidate effector. 
Previously, an $H$. schachtii cellulose-binding protein (CBP) was shown to interact with a host pectin methylesterase (PME) for cooperative cell-wall modification and, ultimately, for syncytium formation to promote parasitism (34). Also, it was proposed that additional proteins might participate in the cell-wall modifications enforced by the CBP-PME interaction (34). Here, we identified a novel $H$. glycines candidate effector that is similar to phytonematode CBPs (Table 1). Although it is very distinct, GLAND10 has highest similarity with $H$. schachtii $\mathrm{CBP}$, not $H$. glycines CBP. This finding of multiple yet variable CBP-like effectors in $H$. glycines demonstrates that the process of cooperative cell-wall modification might involve multiple CBP effectors, which may or may not interact with different host proteins to carry out their functions. Furthermore, CBPs are proposed to have evolved from phytonematode cellulase or expansin cellulose-binding modules (29). Because both cellulases and expansins are believed to been acquired via HGT from bacteria, a phylogenetic analysis with the GLAND10 CBP, additional CBPs, cellulases, and expansins from phytonematodes would be worthwhile for determining the origin of GLAND10 in the genome of $H$. glycines.

Much is known about the omnipresent pathogen effector chorismate mutase $(\mathrm{CM})$. In plant parasitism, secreted CM manipulate the host plant shikimate pathway. CM of root-knot and cyst nematodes $(7,8,19)$ as well as the maize smut fungus Ustilago maydis (18) have been shown to alter plant cell development. It was proposed that these developmental alterations occurred likely through CM lowering auxin levels by causing a competition for chorismate, a central metabolite in the shikimate pathway $(8,19)$. Also, it was suggested that $\mathrm{CM}$ also suppresses the formation of plant defense compounds such as salicylic acid $(8,19)$. GLAND16 has the highest similarity with the $H$. glycines $\mathrm{CM}$ but is also much different, in that its predicted CM domain (Table 2) makes up only a small portion of the protein. The majorities of the GLAND16 N- and C-termini are novel, whereas the previously described $\mathrm{CM}$ effector is mostly just a secreted CM domain (7). This discovery of a novel $H$. glycines candidate effector that has similarity to $\mathrm{CM}$ of phytonematodes but that is also highly different structurally demonstrates that the process of manipulation of the host plant shikimate pathway during parasitism might be more complex than previously understood. Interestingly, the new $H$. glycines CM (GLAND16) putative protein sequence is 1,149 amino acids, which is over four times the size of the previously cloned phytonematode CM and larger than all CMs cloned from any organism. Furthermore, because CMs in phytonematodes have also been proposed to have been acquired via HGT from bacteria (29), a deep phylogenetic analysis for investigating the evolution of this novel CM (GLAND16) gene, in addition to GLAND1 and 13 discussed above, would be particularly interesting.

The syncytium is an elaborate feeding site established by cyst nematodes, most likely through the action of secreted products such as effector proteins $(33,54)$. By exploring the molecular signaling between nematodes and their host plants, it is believed that it is possible to reveal vulnerable points during the parasitic cycle that can be exploited for the development of novel control measures $(33,54)$. For practical applications, interfering with these vulnerable points might allow the engineering of synthetic forms of resistance in the host plants to these nematodes. Furthermore, fundamental knowledge gained through in planta subcellular localization, interaction studies, and reverse genetic approaches for the candidate effectors identified here will greatly strengthen our understanding of how nematodes parasitize plants.

\section{ACKNOWLEDGMENTS}

This is a Journal Paper of the Iowa Agriculture and Home Economics Experiment Station, Ames, supported by Hatch Act and State of Iowa funds. This work was supported by grants from DuPont Pioneer, the United Soybean Board, and USDA-NIFA-AFRI Award 2012-67013-19345. We thank M. Hudson, J. Schmutz, and K. Lambert for providing access to the draft $H$. glycines genome prior to publication. Other than DuPont Pioneer, the funders had no role in study design, data collection and analysis, decision to publish, or preparation of the manuscript.

\section{LITERATURE CITED}

1. Abad, P., Gouzy, J., Aury, J. M., Castagnone-Sereno, P., Danchin, E. G. J., Deleury, E., Perfus-Barbeoch, L., Anthouard, V., Artiguenave, F., Blok, V. C., Caillaud, M. C., Coutinho, P. M., Dasilva, C., De Luca, F., Deau, F., Esquibet, M., Flutre, T., Goldstone, J. V., Hamamouch, N., Hewezi, T., Jaillon, O., Jubin, C., Leonetti, P., Magliano, M., Maier, T. R., Markov, G. V., McVeigh, P., Pesole, G., Poulain, J., Robinson-Rechavi, M., Sallet, E., Segurens, B., Steinbach, D., Tytgat, T., Ugarte, E., van Ghelder, C., Veronico, P., Baum, T. J., Blaxter, M., Bleve-Zacheo, T., Davis, E. L., Ewbank, J. J., Favery, B., Grenier, E., Henrissat, B., Jones, J. T., Laudet, V., Maule, A. G., Quesneville, H., Rosso, M. N., Schiex, T., Smant, G., Weissenbach, J., and Wincker, P. 2008. Genome sequence of the metazoan plant-parasitic nematode Meloidogyne incognita. Nat. Biotechnol. 26: 909-915.

2. Altschul, S. F., Madden, T. L., Schaffer, A. A., Zhang, J. H., Zhang, Z., Miller, W., and Lipman, D. J. 1997. Gapped BLAST and PSI-BLAST: A new generation of protein database search programs. Nucleic Acids Res. 25:3389-3402.

3. Antonino de Souza Junior, J. D., Coelho, R. R., Lourenco, I. T., Fragoso, R. R., Barbosa Viana, A. A., Pepino de Macedo, L. L., Mattar da Silva, M. C., Gomes Carneiro, R. M., Engler, G., de Almeida-Engler, J., and Grossi-de-Sa, M. F. 2013. Knocking-down Meloidogyne incognita proteases by plant-delivered dsRNA has negative pleiotropic effect on nematode vigor. Online publication. PLoS One 8:e85364.

4. Balakirev, M. Y., Tcherniuk, S. O., Jaquinod, M., and Chroboczek, J. 2003. Otubains: A new family of cysteine proteases in the ubiquitin pathway. EMBO Rep. 4:517-522.

5. Baldwin, J. G., Nadler, S. A., and Adams, B. J. 2004. Evolution of plant parasitism among nematodes. Annu. Rev. Phytopathol. 42:83-105.

6. Banfield, D. K. 2011. Mechanisms of protein retention in the golgi. Online publication. Cold Spring Harb. Perspect. Biol. 3:a005264.

7. Bekal, S., Niblack, T. L., and Lambert, K. N. 2003. Chorismate mutase (HG-CM) of the soybean cyst nematode, Heterodera glycines, causes altered root development when expressed in $\mathrm{SCN}$ resistant soybean hairy roots. J. Nematol. 35:325-325.

8. Bekal, S., Niblack, T. L., and Lambert, K. N. 2003. A chorismate mutase from the soybean cyst nematode Heterodera glycines shows polymorphisms that correlate with virulence. Mol. Plant-Microbe Interact. 16: 439-446.

9. Bewley, M. C., Graziano, V., Jiang, J. S., Matz, E., Studier, F. W., Pegg, A. E., Coleman, C. S., and Flanagan, J. M. 2006. Structures of wild-type and mutant human spermidine/spermine N-1-acetyltransferase, a potential therapeutic drug target. Proc. Natl. Acad. Sci. USA 103:2063-2068.

10. Chronis, D., Chen, S. Y., Lu, S. W., Hewezi, T., Carpenter, S. C. D., Loria, R., Baum, T. J., and Wang, X. H. 2013. A ubiquitin carboxyl extension protein secreted from a plant-parasitic nematode Globodera rostochiensis is cleaved in planta to promote plant parasitism. Plant J. 74:185-196.

11. Conley, S. P., Gaska, J. M., Pedersen, P., and Esker, P. 2011. Soybean yield and Heterodera glycines response to rotation, tillage, and genetic resistance. Agron. J. 103:1604-1609.

12. Cotton, J. A., Lilley, C. J., Jones, L. M., Kikuchi, T., Reid, A. J., Thorpe, P., Tsai, I. J., Beasley, H., Blok, V., Cock, P. J., Eves-van den Akker, S., Holroyd, N., Hunt, M., Mantelin, S., Naghra, H., Pain, A., Palomares-Rius, J. E., Zarowiecki, M., Berriman, M., Jones, J. T., and Urwin, P. E. 2014. The genome and life-stage specific transcriptomes of Globodera pallida elucidate key aspects of plant parasitism by a cyst nematodes. Online publication. Genome Biol. 15:R43.

13. Davis, E. L., Hussey, R. S., and Baum, T. J. 2004. Getting to the roots of parasitism by nematodes. Trends Parasitol. 20:134-141.

14. Davis, E. L., Hussey, R. S., Baum, T. J., Bakker, J., and Schots, A. 2000. Nematode parasitism genes. Annu. Rev. Phytopathol. 38:365-396.

15. de Boer, J. M., Yan, Y., Smant, G., Davis, E. L., and Baum, T. J. 1998. Insitu hybridization to messenger RNA in Heterodera glycines. J. Nematol. 30:309-312.

16. Di Cera, E. 2009. Serine Proteases. IUBMB Life 61:510-515.

17. Ding, X., Shields, J., Allen, R., and Hussey, R. S. 1998. A secretory cellulose-binding protein cDNA cloned from the root-knot nematode (Meloidogyne incognita). Mol. Plant-Microbe Interact. 11:952-959.

18. Djamei, A., Schipper, K., Rabe, F., Ghosh, A., Vincon, V., Kahnt, J., Osorio, S., Tohge, T., Fernie, A. R., Feussner, I., Feussner, K., Meinicke, P., Stierhof, Y. D., Schwarz, H., Macek, B., Mann, M., and Kahmann, R. 2011. Metabolic priming by a secreted fungal effector. Nature 478: 395-398. 
19. Doyle, E. A., and Lambert, K. N. 2003. Meloidogyne javanica chorismate mutase 1 alters plant cell development. Mol. Plant-Microbe Interact. 16: 123-131.

20. Draker, K. A., and Wright, G. D. 2004. Molecular mechanism of the enterococcal aminoglycoside 6'-N-acetyltransferase': Role of GNATconserved residues in the chemistry of antibiotic inactivation. Biochemistry 43:446-454.

21. Elling, A. A., Davis, E. L., Hussey, R. S., and Baum, T. J. 2007. Active uptake of cyst nematode parasitism proteins into the plant cell nucleus. Int. J. Parasitol. 37:1269-1279.

22. Elling, A. A., Mitreva, M., Gai, X. W., Martin, J., Recknor, J., Davis, E. L., Hussey, R. S., Nettleton, D., McCarter, J. P., and Baum, T. J. 2009. Sequence mining and transcript profiling to explore cyst nematode parasitism. Online publication. BMC Genomics 10:58.

23. Ewing, B., and Green, P. 1998. Base-calling of automated sequencer traces using phred. II. Error probabilities. Genome Res. 8:186-194.

24. Ewing, B., Hillier, L., Wendl, M. C., and Green, P. 1998. Base-calling of automated sequencer traces using phred. I. Accuracy assessment. Genome Res. 8:175-185.

25. Gao, B. L., Allen, R., Davis, E. L., Baum, T. J., and Hussey, R. S. 2004. Molecular characterisation and developmental expression of a cellulosebinding protein gene in the soybean cyst nematode Heterodera glycines. Int. J. Parasitol. 34:1377-1383.

26. Gao, B. L., Allen, R., Maier, T., Davis, E. L., Baum, T. J., and Hussey, R. S. 2001. Identification of putative parasitism genes expressed in the esophageal gland cells of the soybean cyst nematode Heterodera glycines. Mol. Plant-Microbe Interact. 14:1247-1254.

27. Gao, B. L., Allen, R., Maier, T., Davis, E. L., Baum, T. J., and Hussey, R. S. 2003. The parasitome of the phytonematode Heterodera glycines. Mol. Plant-Microbe Interact. 16:720-726.

28. Guo, Y., Ni, J., Denver, R., Wang, X., and Clark, S. E. 2011. Mechanisms of molecular mimicry of plant CLE peptide ligands by the parasitic nematode Globodera rostochiensis. Plant Physiol. 157:476-484.

29. Haegeman, A., Jones, J. T., and Danchin, E. G. J. 2011. Horizontal gene transfer in nematodes: A catalyst for plant parasitism? Mol. Plant-Microbe Interact. 24:879-887.

30. Hamamouch, N., Li, C., Hewezi, T., Baum, T. J., Mitchum, M. G., Hussey, R. S., Vodkin, L. O., and Davis, E. L. 2012. The interaction of the novel $30 \mathrm{C} 02$ cyst nematode effector protein with a plant beta-1,3-endoglucanase may suppress host defence to promote parasitism. J. Exp. Bot. 63:3683-3695.

31. Han, Q., Robinson, H., Ding, H. Z., Christensen, B. M., and Li, J. Y. 2012. Evolution of insect arylalkylamine $\mathrm{N}$-acetyltransferases: Structural evidence from the yellow fever mosquito, Aedes aegypti. Proc. Natl. Acad. Sci. USA 109:11669-11674.

32. Haouazine-Takvorian, N., Tymowska-Lalanne, Z., Takvorian, A., Tregear, J., Lejeune, B., Lecharny, A., and Kreis, M. 1997. Characterization of two members of the Arabidopsis thaliana gene family, At $\beta$ fruct 3 and Atßfruct4, coding for vacuolar invertases. Gene 197:239-251.

33. Hewezi, T., and Baum, T. J. 2013. Manipulation of plant cells by cyst and root-knot nematode effectors. Mol. Plant-Microbe Interact. 26:9-16.

34. Hewezi, T., Howe, P., Maier, T. R., Hussey, R. S., Mitchum, M. G., Davis, E. L., and Baum, T. J. 2008. Cellulose binding protein from the parasitic nematode Heterodera schachtii interacts with Arabidopsis pectin methylesterase: cooperative cell wall modification during parasitism. Plant Cell 20:3080-3093.

35. Hewezi, T., Howe, P. J., Maier, T. R., Hussey, R. S., Mitchum, M. G., Davis, E. L., and Baum, T. J. 2010. Arabidopsis spermidine synthase is targeted by an effector protein of the cyst nematode Heterodera schachtii. Plant Physiol. 152:968-984.

36. Huang, G. A., Gao, B. L., Maier, T., Allen, R., Davis, E. L., Baum, T. J., and Hussey, R. S. 2003. A profile of putative parasitism genes expressed in the esophageal gland cells of the root-knot nematode Meloidogyne incognita. Mol. Plant-Microbe Interact. 16:376-381.

37. Hussey, R. S. 1989. Disease-inducing secretions of plant-parasitic nematodes. Annu. Rev. Phytopathol. 27:123-141.

38. Hussey, R. S., and Grundler, F. M. W. 1998. Nematode parasitism of plants. Pages 213-243 in: The Physiology and Biochemistry of FreeLiving and Plant-Parasitic Nematodes. R. N. Perry and D. J. Wright, eds. CAB International, Wallingford, UK.

39. Jacobson, S., and Pillus, L. 1999. Modifying chromatin and concepts of cancer. Curr. Opin. Genet. Dev. 9:175-184.

40. Kaplan, I., Sardanelli, S., Rehill, B. J., and Denno, R. F. 2011. Toward a mechanistic understanding of competition in vascular-feeding herbivores: An empirical test of the sink competition hypothesis. Oecologia 166: 627-636.

41. Kaushal, D., and Clayton, W. 2004. Loading and preparing data for analysis in Spotfire. Online publication. Curr. Protocols Bioinf. Unit 7.8. doi:10.1002/0471250953.bi0708s6.
42. Kim, K. H., An, D. R., Song, J., Yoon, J. Y., Kim, H. S., Yoon, H. J., Im, H. N., Kim, J., Kim, D. J., Lee, S. J., Lee, H. M., Kim, H. J., Jo, E. K., Lee, J. Y., and Suh, S. W. 2012. Mycobacterium tuberculosis Eis protein initiates suppression of host immune responses by acetylation of DUSP16/MKP-7. Proc. Natl. Acad. Sci. USA 109:7729-7734.

43. Koenning, S.R., and Wrather, J.A. 2010. Suppression of soybean yield potential in the continental United States by plant diseases from 2006 to 2009. Online publication. Plant Health Prog. doi:10.1094/PHP-20101122-01-RS.

44. Krogh, A., Larsson, B., von Heijne, G., and Sonnhammer, E. L. L. 2001. Predicting transmembrane protein topology with a hidden Markov model: Application to complete genomes. J. Mol. Biol. 305:567-580.

45. Lambert, K. N., Allen, K. D., and Sussex, I. M. 1999. Cloning and characterization of an esophageal-gland-specific chorismate mutase from the phytoparasitic nematode Meloidogyne javanica. Mol. Plant-Microbe Interact. 12:328-336.

46. Lee, A. H. Y., Hurley, B., Felsensteiner, C., Yea, C., Ckurshumova, W., Bartetzko, V., Wang, P. W., Quach, V., Lewis, J. D., Liu, Y. L. C., Bornke, F., Angers, S., Wilde, A., Guttman, D. S., and Desveaux, D. 2012. A bacterial acetyltransferase destroys plant microtubule networks and blocks secretion. Online publication. PLoS Pathog. 8:e1002523.

47. Lee, C., Chronis, D., Kenning, C., Peret, B., Hewezi, T., Davis, E. L., Baum, T. J., Hussey, R., Bennett, M., and Mitchum, M. G. 2011. The novel cyst nematode effector protein 19C07 interacts with the Arabidopsis auxin influx transporter LAX3 to control feeding site development. Plant Physiol. 155:866-880.

48. Liu, S. M., Kandoth, P. K., Warren, S. D., Yeckel, G., Heinz, R., Alden, J., Yang, C. L., Jamai, A., El-Mellouki, T., Juvale, P. S., Hill, J., Baum, T. J., Cianzio, S., Whitham, S. A., Korkin, D., Mitchum, M. G., and Meksem, K. 2012. A soybean cyst nematode resistance gene points to a new mechanism of plant resistance to pathogens. Nature 492:256-260.

49. Lomsadze, A., Ter-Hovhannisyan, V., Chernoff, Y. O., and Borodovsky, M. 2005. Gene identification in novel eukaryotic genomes by self-training algorithm. Nucleic Acids Res. 33:6494-6506.

50. Lozano-Torres, J. L., Wilbers, R. H. P., Gawronski, P., Boshoven, J. C., Finkers-Tomczak, A., Cordewener, J. H. G., America, A. H. P., Overmars, H. A., Van 't Klooster, J. W., Baranowski, L., Sobczak, M., Ilyas, M., van der Hoorn, R. A. L., Schots, A., de Wit, P. J. G. M., Bakker, J., Goverse, A., and Smant, G. 2012. Dual disease resistance mediated by the immune receptor $\mathrm{Cf}-2$ in tomato requires a common virulence target of a fungus and a nematode. Proc. Natl. Acad. Sci. USA 109:10119-10124.

51. Maier, T. R., Hewezi, T., Peng, J., and Baum, T. J. 2013. Isolation of whole esophageal gland cells from plant-parasitic nematodes for transcriptome analyses and effector identification. Mol. Plant-Microbe Interact. 26:31-35.

52. Marchler-Bauer, A., Lu, S. N., Anderson, J. B., Chitsaz, F., Derbyshire, M. K., DeWeese-Scott, C., Fong, J. H., Geer, L. Y., Geer, R. C., Gonzales, N. R., Gwadz, M., Hurwitz, D. I., Jackson, J. D., Ke, Z. X., Lanczycki, C. J., Lu, F., Marchler, G. H., Mullokandov, M., Omelchenko, M. V., Robertson, C. L., Song, J. S., Thanki, N., Yamashita, R. A., Zhang, D. C., Zhang, N. G., Zheng, C. J., and Bryant, S. H. 2011. CDD: A Conserved Domain Database for the functional annotation of proteins. Nucleic Acids Res. 39:D225-D229.

53. Matas, I. M., Castaneda-Ojeda, M. P., Aragon, I. M., Antunez-Lamas, M., Murillo, J., Rodriguez-Palenzuela, P., Lopez-Solanilla, E., and Ramos, C. 2014. Translocation and Functional Analysis of Pseudomonas savastanoi pv. savastanoi NCPPB 3335 type III secretion system effectors reveals two novel effector families of the Pseudomonas syringae complex. Mol. Plant-Microbe Interact. 27:424-436.

54. Mitchum, M. G., Hussey, R. S., Baum, T. J., Wang, X. H., Elling, A. A., Wubben, M., and Davis, E. L. 2013. Nematode effector proteins: An emerging paradigm of parasitism. New Phytol. 199:879-894.

55. Nakai, K., and Horton, P. 1999. PSORT: A program for detecting the sorting signals of proteins and predicting there subcellular localization. Trends Biochem. Sci. 24:34-35.

56. Neveu, C., Abad, P., and Castagnone-Sereno, P. 2003. Molecular cloning and characterization of an intestinal cathepsin L protease from the plantparasitic nematode Meloidogyne incognita. Physiol. Mol. Plant Pathol. 63:159-165.

57. Paquette, N., Conlon, J., Sweet, C., Rus, F., Wilson, L., Pereira, A., Rosadini, C. V., Goutagny, N., Weber, A. N. R., Lane, W. S., Shaffer, S. A., Maniatis, S., Fitzgerald, K. A., Stuart, L., and Silverman, N. 2012. Serine/threonine acetylation of TGF beta-activated kinase (TAK1) by Yersinia pestis YopJ inhibits innate immune signaling. Proc. Natl. Acad. Sci. USA 109:12710-12715.

58. Patel, N., Hamamouch, N., Li, C. Y., Hewezi, T., Hussey, R. S., Baum, T. J., Mitchum, M. G., and Davis, E. L. 2010. A nematode effector protein similar to annexins in host plants. J. Exp. Bot. 61:235-248. 
59. Petersen, T. N., Brunak, S., von Heijne, G., and Nielsen, H. 2011. SignalP 4.0: Discriminating signal peptides from transmembrane regions. Nat. Methods 8:785-786.

60. Postma, W. J., Slootweg, E. J., Rehman, S., Finkers-Tomczak, A., Tytgat, T. O. G., van Gelderen, K., Lozano-Torres, J. L., Roosien, J., Pomp, R., van Schaik, C., Bakker, J., Goverse, A., and Smant, G. 2012. The effector SPRYSEC-19 of Globodera rostochiensis suppresses CC-NB-LRRmediated disease resistance in plants. Plant Physiol. 160:944-954.

61. Prasad, C. S., Gupta, S., Kumar, H., and Tiwari, M. 2013. Evolutionary and functional analysis of fructose bisphosphate aldolase of plant parasitic nematodes. Bioinformation 9:1-8.

62. Qin, L., Overmars, B., Helder, J., Popeijus, H., van der Voort, J. R., Groenink, W., van Koert, P., Schots, A., Bakker, J., and Smant, G. 2000. An efficient cDNA-AFLP-based strategy for the identification of putative pathogenicity factors from the potato cyst nematode Globodera rostochiensis. Mol. Plant-Microbe Interact. 13:830-836.

63. Quevillon, E., Silventoinen, V., Pillai, S., Harte, N., Mulder, N., Apweiler, R., and Lopez, R. 2005. InterProScan: Protein domains identifier. Nucleic Acids Res. 33:W116-W120.

64. Replogle, A., Wang, J. Y., Bleckmann, A., Hussey, R. S., Baum, T. J., Sawa, S., Davis, E. L., Wang, X. H., Simon, R., and Mitchum, M. G. 2011. Nematode CLE signaling in Arabidopsis requires CLAVATA2 and CORYNE. Plant J. 65:430-440.

65. Sanches, M., Alves, B. S. C., Zanchin, N. I. T., and Guimaraes, B. G. 2007. The crystal structure of the human Mov34 MPN domain reveals a metal-free dimer. J. Mol. Biol. 370:846-855.

66. Scholl, E. H., Thorne, J. L., McCarter, J. P., and Bird, D. M. 2003. Horizontally transferred genes in plant-parasitic nematodes: A highthroughput genomic approach. Online publication. Genome Biol. 4:R39.

67. Smant, G., Stokkermans, J., Yan, Y. T., de Boer, J. M., Baum, T. J., Wang, X. H., Hussey, R. S., Gommers, F. J., Henrissat, B., Davis, E. L., Helder, J., Schots, A., and Bakker, J. 1998. Endogenous cellulases in animals: Isolation of beta-1,4-endoglucanase genes from two species of plantparasitic cyst nematodes. Proc. Natl. Acad. Sci. USA 95:4906-4911.

68. Sonnhammer, E. L., von Heijne, G., and Krogh, A. 1998. A hidden Markov model for predicting transmembrane helices in protein sequences. Proc. Int. Conf. Intell. Syst. Mol. Biol. 6:175-182.
69. Subbotin, S., Mundo-Ocampo, M., and Baldwin, J. G. 2010. Systematics of Cyst Nematodes (Nematoda: Heteroderinae). Brill Academic Publishers, Leiden, Netherlands.

70. Thorpe, P., Mantelin, S., Cock, P. J. A., Blok, V. C., Coke, M. C., Eves-van den Akker, S., Guzeeva, E., Lilley, C. J., Smant, G., Reid, A. J., Wright, K. M., Urwin, P. E., and Jones, J. T. 2014. Genomic characterisation of the effector complement of the potato cyst nematode Globodera pallida. Online publication. BMC Genomics 15:923.

71. Toubarro, D., Lucena-Robles, M., Nascimento, G., Santos, R., Montiel, R., Verissimo, P., Pires, E., Faro, C., Coelho, A. V., and Simoes, N. 2010. Serine Protease-mediated Host Invasion by the Parasitic Nematode Steinernema carpocapsae. J. Biol. Chem. 285:30666-30675.

72. Tytgat, T., Vanholme, B., De Meutter, J., Claeys, M., Couvreur, M., Vanhoutte, I., Gheysen, G., Van Criekinge, W., Borgonie, G., and Coomans, A. 2004. A new class of ubiquitin extension proteins secreted by the dorsal pharyngeal gland in plant parasitic cyst nematodes. Mol. Plant-Microbe Interact. 17:846-852.

73. Vanholme, B., Van Thuyne, W., Vanhouteghem, K., De Meutter, J., Cannoot, B., and Gheysen, G. 2007. Molecular characterization and functional importance of pectate lyase secreted by the cyst nematode Heterodera schachtii. Mol. Plant Pathol. 8:267-278.

74. Wang, J., Replogle, A., Hussey, R., Baum, T., Wang, X., Davis, E. L., and Mitchum, M. G. 2011. Identification of potential host plant mimics of CLAVATA3/ESR (CLE)-like peptides from the plant-parasitic nematode Heterodera schachtii. Mol. Plant Pathol. 12:177-186.

75. Wang, X. H., Allen, R., Ding, X. F., Goellner, M., Maier, T., de Boer, J. M., Baum, T. J., Hussey, R. S., and Davis, E. L. 2001. Signal peptideselection of cDNA cloned directly from the esophageal gland cells of the soybean cyst nematode Heterodera glycines. Mol. Plant-Microbe Interact. 14:536-544.

76. Wang, X. H., Mitchum, M. G., Gao, B. L., Li, C. Y., Diab, H., Baum, T. J., Hussey, R. S., and Davis, E. L. 2005. A parasitism gene from a plantparasitic nematode with function similar to CLAVATA3/ESR (CLE) of Arabidopsis thaliana. Mol. Plant Pathol. 6:187-191.

77. Wu, H. X., Jones, R. M., and Neish, A. S. 2012. The Salmonella effector AvrA mediates bacterial intracellular survival during infection in vivo. Cell. Microbiol. 14:28-39. 